\title{
Effect of Boundary Conditions on the Behavior of Stiffened and Un-Stiffened Cylindrical Shells
}

\author{
Oussama Temami ${ }^{1} \cdot$ Ashraf Ayoub $^{2}$ (D) $\cdot$ Djamal Hamadi ${ }^{3} \cdot$ Imed Bennoui $^{4}$
}

Received: 29 November 2017 / Accepted: 3 October 2018 / Published online: 15 October 2018

(c) The Author(s) 2018

\begin{abstract}
The effect of boundary conditions is very important in the analysis of cylindrical shells, and is rarely studied in the literature due to its difficult experimental simulation. For large structures such as shell roofs, the type of boundary supports is among the major factors that can minimize the stresses and deflections. In this study, experimental and numerical investigations of the effect of different boundary supports for stiffened and un-stiffened cylindrical shells were conducted. Two different models of the stiffened and un-stiffened cylindrical shells with different boundary conditions, "pinned and with rigid diaphragms", were studied. It was shown that by using rigid diaphragms for cylindrical shells, the deflections are minimized by $80 \%$, and by (45-50) \% for the stiffened cylindrical shells. From the experimental investigations and the numerical results obtained, the efficiency of the proposed boundary support types for cylindrical shells is confirmed, which can result in economic benefits.
\end{abstract}

Keywords Cylindrical shell $\cdot$ Shell element $\cdot$ Stiffeners $\cdot$ Rigid diaphragms $\cdot$ Boundary supports

\section{Introduction}

The boundary conditions of shell structures have an important effect on the state of stresses and the values of displacements. The rigid clamping of the edges of shell structures induces bending stresses at least over a narrow zone near the boundaries, and also prevents the structure from undergoing extensional deformations. The analysis of cylindrical shells with different boundary conditions is infrequently studied in the literature; this is mostly due to experimental

Ashraf Ayoub

Ashraf.Ayoub.1@city.ac.uk

1 Department of Civil Engineering, Faculty of Technology Science, Mentouri Brothers University, Ain El Bey Street, B.P. 325, 25017 Constantine, Algeria

2 School of Mathematics, Computer Science and Engineering, City, University of London, Northampton Square, London EC1V OHB, UK

3 Laboratory of Civil Engineering, Hydraulics, Development and Durability, Department of Civil Engineering and Hydraulics, Biskra University, B.P. 145 RP, 07000 Biskra, Algeria

4 Laboratory of Public Works Engineering and Environment (LTPITE), High National School of Public Works (ENSTP) 1, Sidi Garidi Street, B.P. 32 Vieux Kouba, 16051 Algiers, Algeria difficulties. This problem also exists in many marine, aerospace and automotive engineering applications. The three main approaches involved in structural identification of behavior are the theoretical analysis, numerical simulation, and experimental investigation.

In a classical research, Flügge (1934) derived a set of cylindrical shell equations which included bending terms up to the second order. He did not solve the problem in its most general form, but suggested a solution for a simply supported cylindrical shell, in the form of trigonometric functions which satisfied the boundary conditions. This is certainly the reason this approach is not feasible after the advent of high-speed digital computers. Although the method requires numerical computation, the results are exact in the same sense that the numerical solution to the transcendental frequency equation for a beam yields an exact solution. Another study published by Sobel (1964) is on the closely related area of stability of cylindrical shells. The results of these two independent studies lead to the same conclusions regarding the importance of the various boundary conditions of cylindrical shells. Forsberg (1964) studied the influence of boundary conditions on the model characteristics of thin cylindrical shells; his research related to Flugge's and Sobel's studies, and his approach provides a powerful tool for examining a wide variety of boundary conditions and their influence on the modal behavior of 
cylindrical shells. The results of this study clearly indicate that care must be taken in any approximate analysis to use appropriate boundary conditions. An axisymmetric and an unsymmetrical analysis of conical and cylindrical shells with various boundary conditions were conducted by Wilkins et al. (1970). Chebili (1991) studied the problem of deformation of shells and found that the behavior is governed by both the geometry of the shell and its boundary supports. Skukis et al. (2013) studied the assessment of the effect of boundary conditions on cylindrical shell modal responses. In his study, a circular cylindrical shell employing arbitrary boundary conditions has been fabricated and physically tested, with several boundary conditions being used during the experimental setup. A numerical verification with the finite element code ANSYS has been performed in parallel in order to demonstrate the accuracy of the current solutions. Marchuk and Gnidash (2016) proposed two approaches for the analysis of the thick-walled cylindrical shells with different boundary conditions under local loads. It is shown that the effect of the boundary conditions on the stress-strain state is very weak for shells of high curvature and strong for shells of low curvature.

The present research is focusing on an assessment of boundary conditions and edge beam effects on the vertical and horizontal displacement of cylindrical shells. For this purpose; five semi cylindrical shell models with diameters of $32 \mathrm{~cm}$ are fabricated from stainless steel 304 grade, two of them with stiffeners. The deflection measurements have been performed by means of 50-C9842 ADVANTEST 9. Two different boundary conditions were used during the experimental investigation: Pinned at four points and fixed by two rigid diaphragms. The numerical analysis is performed by a flat shell finite element called "ACM-RSBE5" developed by Hamadi et al. (2015) and the "S4R, C3D8IH" developed by ABAQUS (2014). The modal characteristics and the vertical

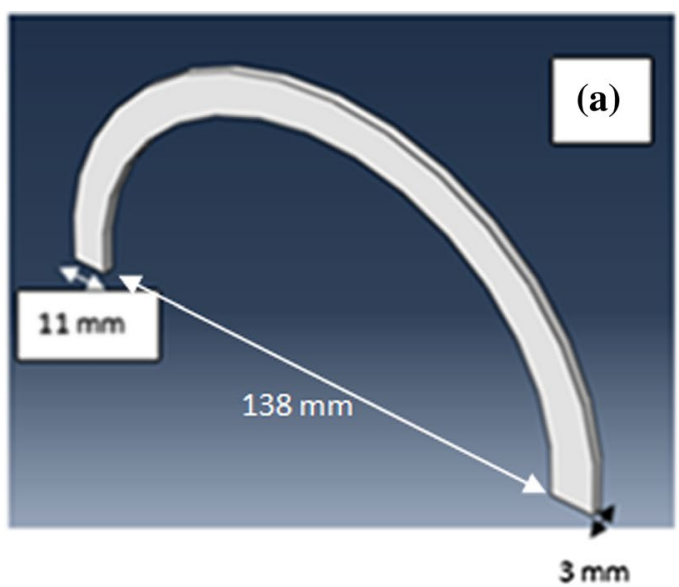

displacements are evaluated and the effect of various boundary conditions is discussed.

\section{Analysis Approach}

\subsection{Geometry and Mechanical Properties of the Cylindrical Shell Models}

The specimens have been produced by rolling of thin stainless steel sheet of 304 grade $(t=1.2 \mathrm{~mm})$, to form the semi cylindrical shell structure. Five semi cylindrical models were used, two with stiffeners, one with stiffeners reposed on edge beams and two without stiffeners. Two different boundary conditions were considered; the first reposed on 4 points "pinned", and the second reposed on two rigid diaphragms "fixed". We proposed that the rigid diaphragms be welded to the semi cylinder to facilitate the experimental work. The dimensions of the semi cylinder are; the diameter is $\mathrm{D}=320 \mathrm{~mm}$ and the length $\mathrm{L}=900 \mathrm{~mm}$, the thickness is the same for all specimens, the material properties are: the Young's modulus $\mathrm{E}=190,000 \mathrm{~N} / \mathrm{mm}^{2}$, and the Poisson ratio $v=0.265$. A concentrated load is applied at the center of the top of the shell for all models.

In this work, two types of stiffeners are used; ring stiffeners and stringers, both of them have the same material properties as the shell. Figure 1 shows the geometrical properties of the ring stiffeners and the stringers "edge beams". Figures $2 a, b$ and 3 present the positioning of the stiffeners and edge beams on the cylindrical shell.

\subsection{Finite Element Study}

The numerical analyses have been performed by employing three finite elements, the first one is the called (b)

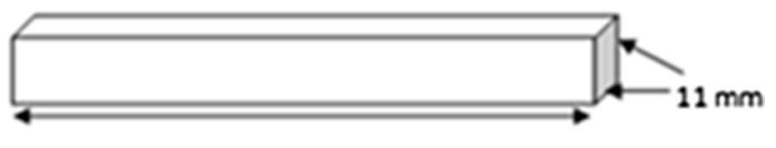

$900 \mathrm{~mm}$

Fig. 1 Geometrical dimensions of the stiffeners. a Ring stiffeners. b Stringers "Edge beam" 

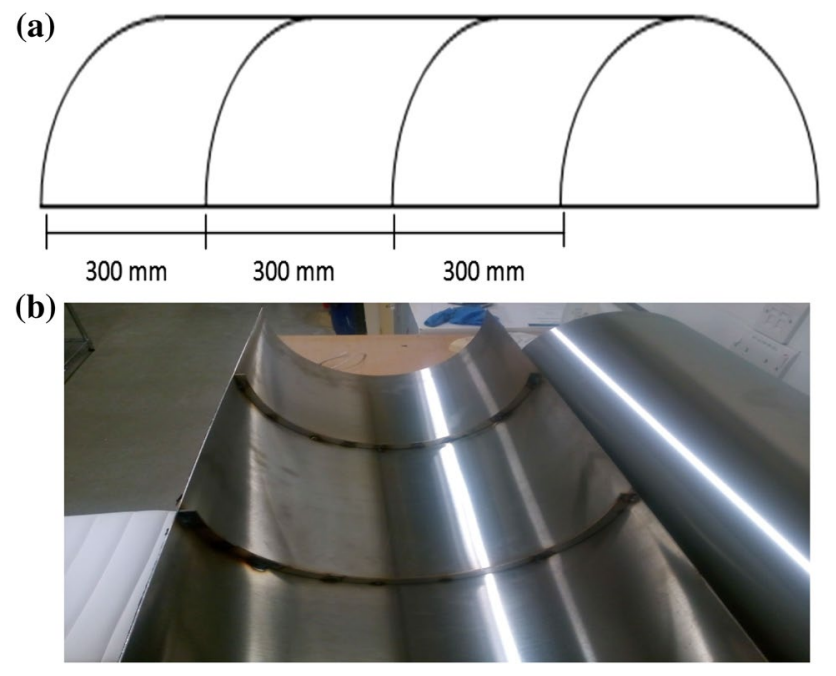

Fig. 2 Positioning of the stiffeners at the cylinder $(\mathbf{a}, \mathbf{b})$

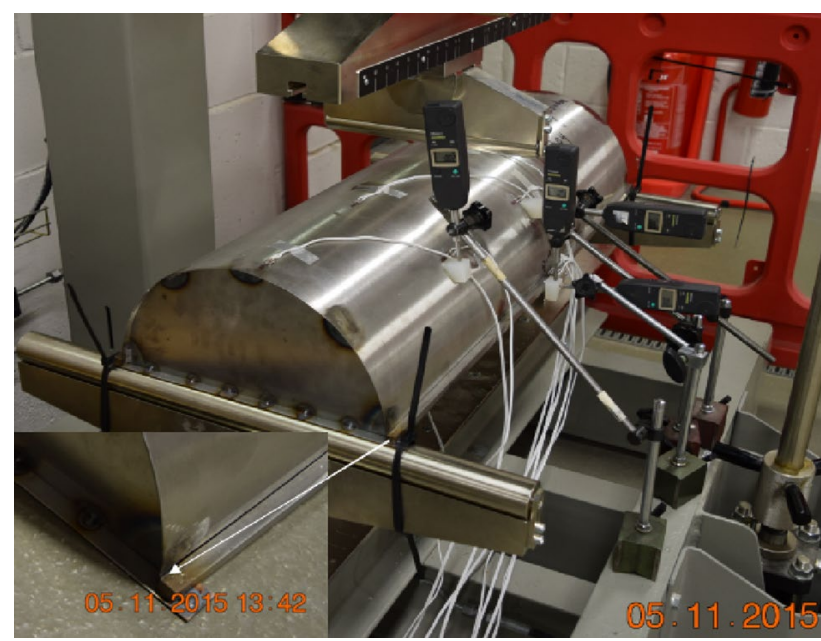

Fig. 3 Positioning of edge beams on the cylindrical shell

"ACM-RSBE5" element, and the two other elements are: the S4R and C3D8IH elements of the commercial ABAQUS code. Figure 4 presents the meshing for the finite element model used $(45 \times 25$ elements $)$.

\subsubsection{Description of "ACM-RSBE5" Element}

The ACM-RSBE5 is a rectangular flat shell element, obtained by the superposition of the RSBE5 membrane strain-based finite element with the ACM standard plate bending element originally developed by Adini and Clough (1961) and Melosh (1963). The shell element obtained ACM_RSBE5 is composed by assembling the two elements RSBE5 and ACM with an effective rotation $\mathrm{z}$ (see Fig. 5).
The stiffness matrix of the shell element ACM-RSBE5 is obtained by using the analytical integration of the membrane and bending stiffness matrix. The calculation of the element stiffness matrix is summarized with the following well known expressions:

$\left[K_{e}\right]=\left[A^{-1}\right]^{T}\left[\iint_{S}[Q]^{T}[D][Q] d x d y\right]\left[A^{-1}\right]$

$\left[K_{e}\right]=\left[A^{-1}\right]^{T}\left[K_{0}\right]\left[A^{-1}\right]$

$\left[K_{0}\right]=\iint_{\mathrm{s}}[Q]^{\mathrm{T}}[D][Q] d x d y$

where $(D)$ the constitutive matrix, $(A)$ the transformation matrix, $(Q)$ the strain matrix, and $\left(K_{e}\right)$ is the elementary stiffness matrix.

\subsubsection{Description of S4R ABAQUS Element}

The S4R is a 4-node doubly curved element used for thin and thick shells. It has 6 DOF at each node, and its stiffness matrix is calculated using a reduced integration and hourglass control.

\subsubsection{Description of C3D8IH ABAQUS Element}

The C3D8IH element is a general purpose linear brick element, with full integration points, hybrid formulation and incompatible modes. The node numbering follows the convention as shown in (Fig. 6).

\subsection{Experimental Tests}

The main purpose of this experimental investigation is to study the efficiency of boundary conditions, stiffeners and edge beams, on the cylindrical shells. To carry this investigation, two experimental models are carried out. For the first one; two semi cylinder models with different boundary conditions are considered; pinned and fixed supports; and for the second one, two models; stiffened semi cylindrical shells with different boundary conditions, pinned and fixed are investigated. Figure 7 presents the UNIFLEX 300 machine and the shell model setup, and also presents the positioning of dial gauges. Figure 8a, b present the different boundary conditions used, and Fig. 9 shows the positioning of the stiffeners. Figure 10 presents the stiffened cylindrical shell reposed on rigid diaphragm and edge beams. 


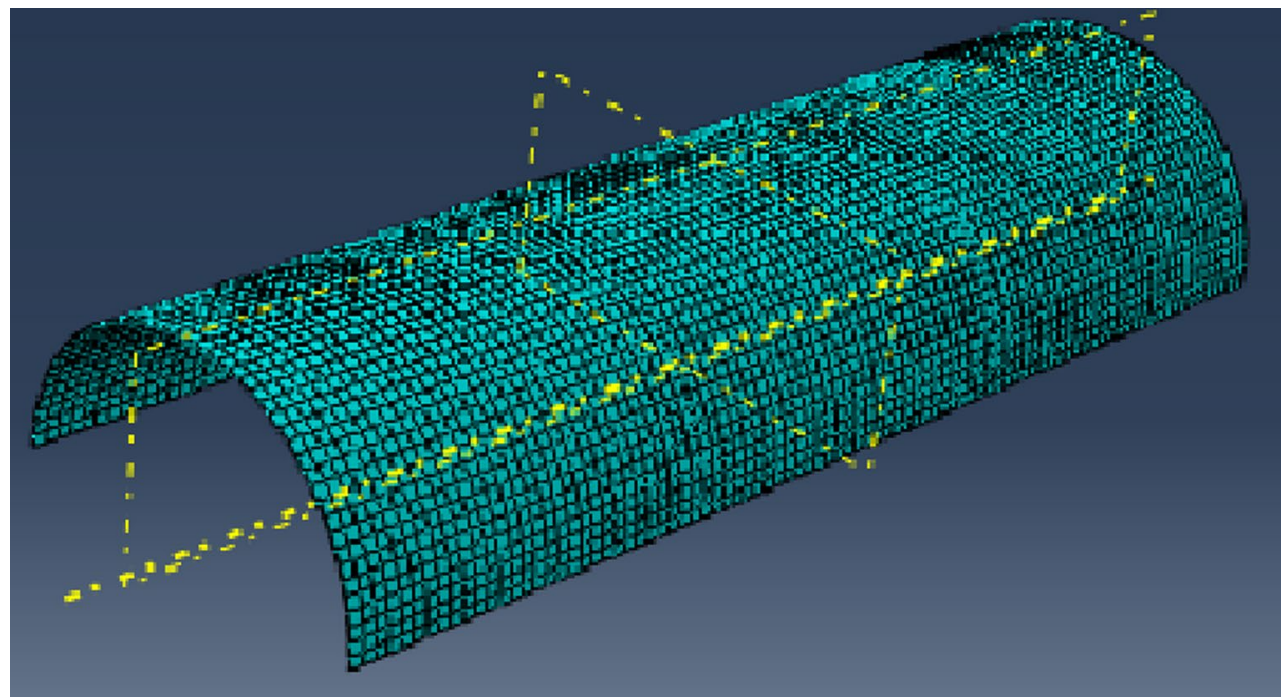

Fig. 4 Finite element mesh

Fig. 5 The shell element ACMRSBE5

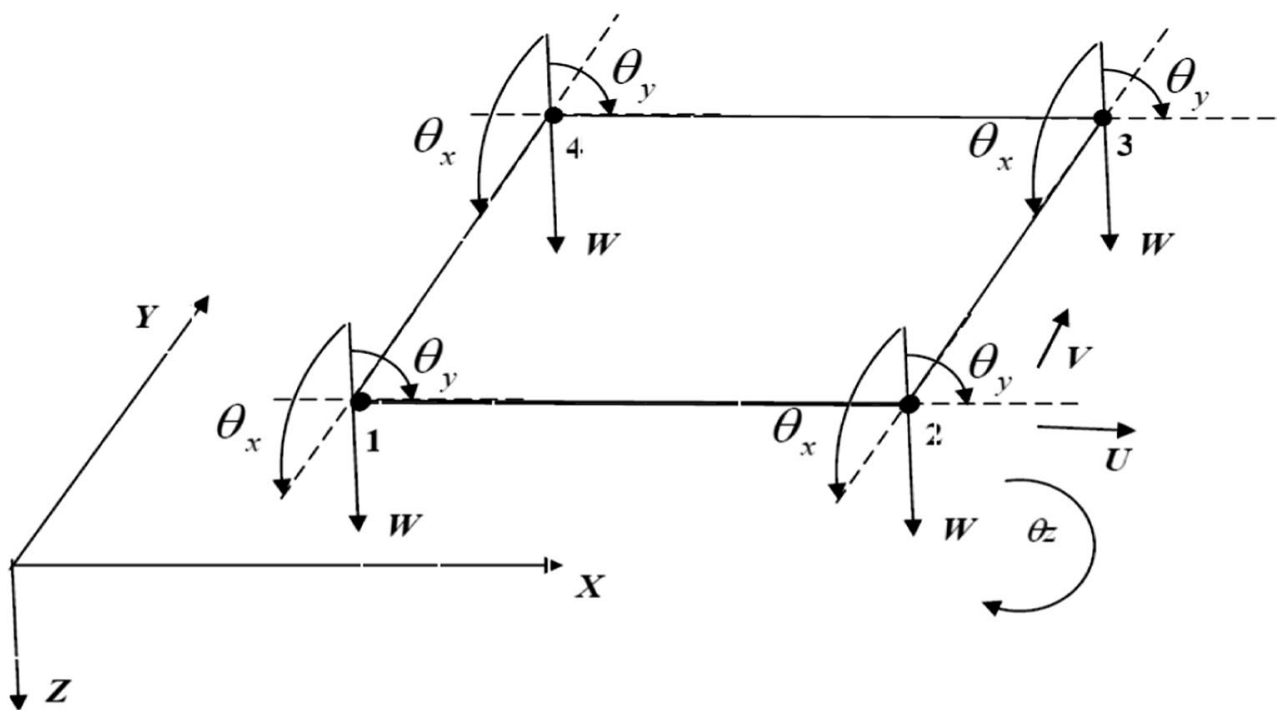

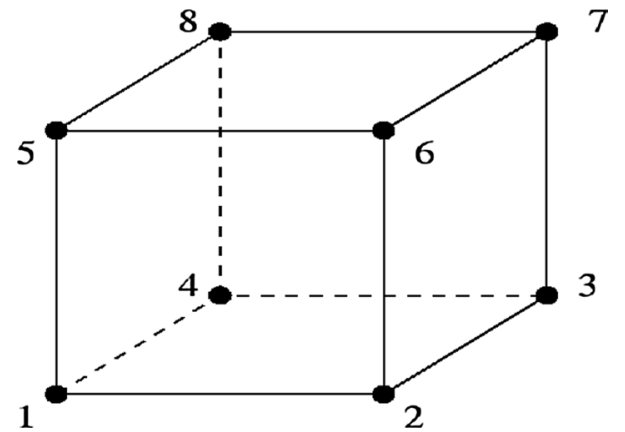

Fig. 6 8-Node brick element

We choose three points 1, 2 and 3 to record the displacement; which is given by the apparatus ADVANTEST 9 and the dial gauges (Fig. 11). The point of applied load is the top of the semi cylinder, as illustrated in Fig. 7; it is the same point where the deflection is recorded. The applied load is a concentrated static load for all tests. The structure is controlled by a vertical rod hydraulically clamped and controlled assuring high rigidity, fitted with high precision load cells for accurate and reliable test results. The tests were conducted under control of displacements performed with the ADVANTEST 9 (servo-hydraulic control console). 


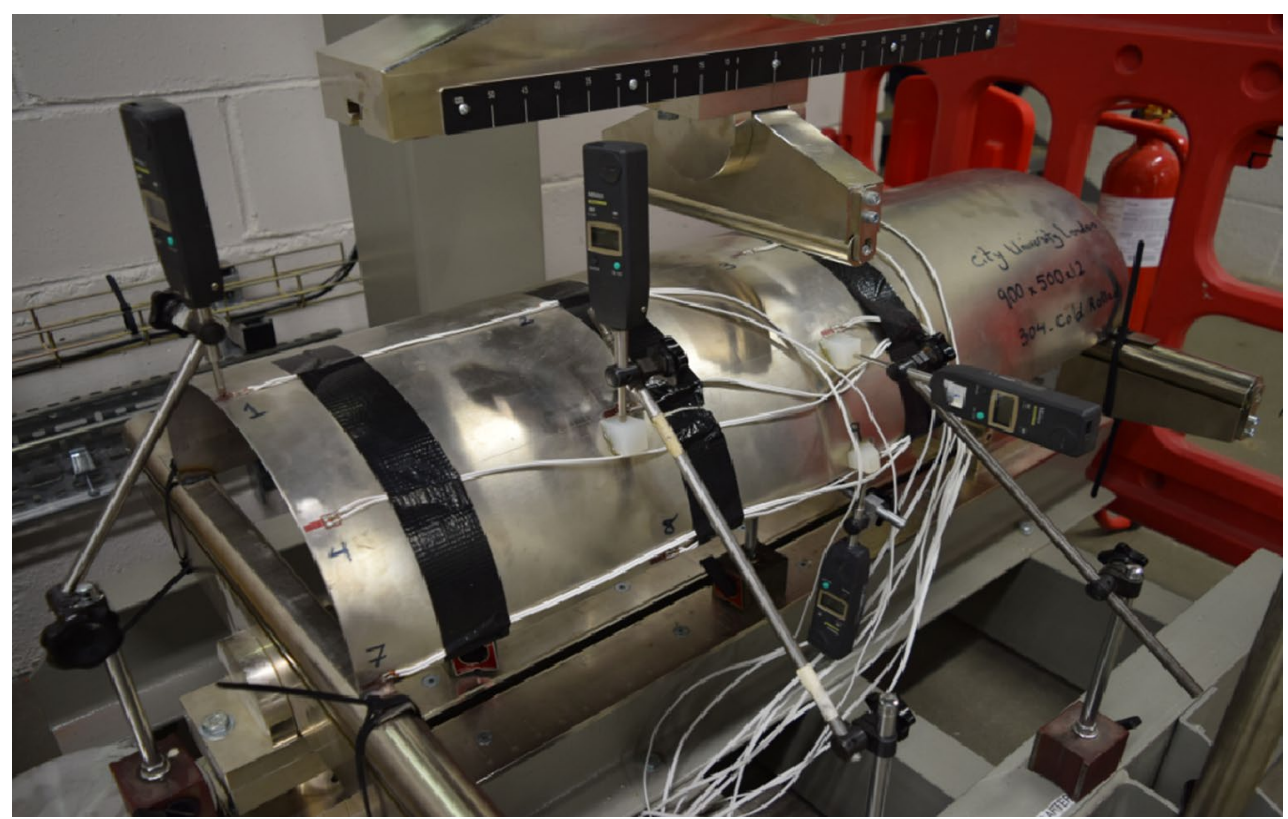

Fig. 7 The shell model setup
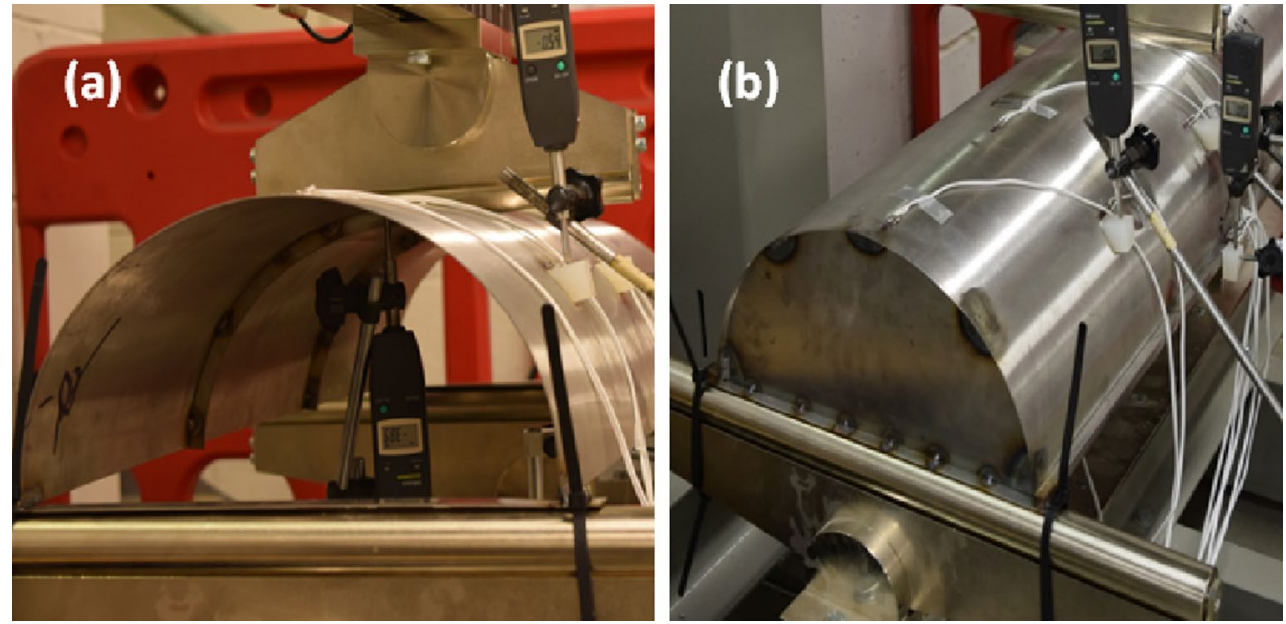

Fig. 8 a Cylindrical shell reposed on four points "pinned". b Cylindrical shell reposed on rigid diaphragm "fixed"

\section{Effect of Boundary Conditions on the Behavior of Cylindrical Shells}

For the study of the effectiveness of boundary conditions, two types of semi cylindrical shells with different boundary conditions are considered:

- Cylindrical shell supported on 4 points "pinned" CS4P.

- Cylindrical shell supported on two ends "Rigid Diaphragms" CSRD.
In this comparison, the following loads are applied $(775 \mathrm{~N}, 800 \mathrm{~N}, 825 \mathrm{~N}, 850 \mathrm{~N}, 875 \mathrm{~N}$ and $900 \mathrm{~N})$. Table 1 shows the results obtained from the experimental test, as well as the flat shell element ACM-RSBE5 and ABAQUS code with meshes of $10 \times 10$ elements. The results indicate that the finite element models slightly under-predicted the displacements at higher load levels. This can be attributed to the settlement of the test setup observed in the experiment.

The results obtained for the cylindrical shell model supported on two ends "Rigid Diaphragms" are presented in Table 1 . In this case the finite element model slightly overpredicted the displacements since it assumed a fully rigid 


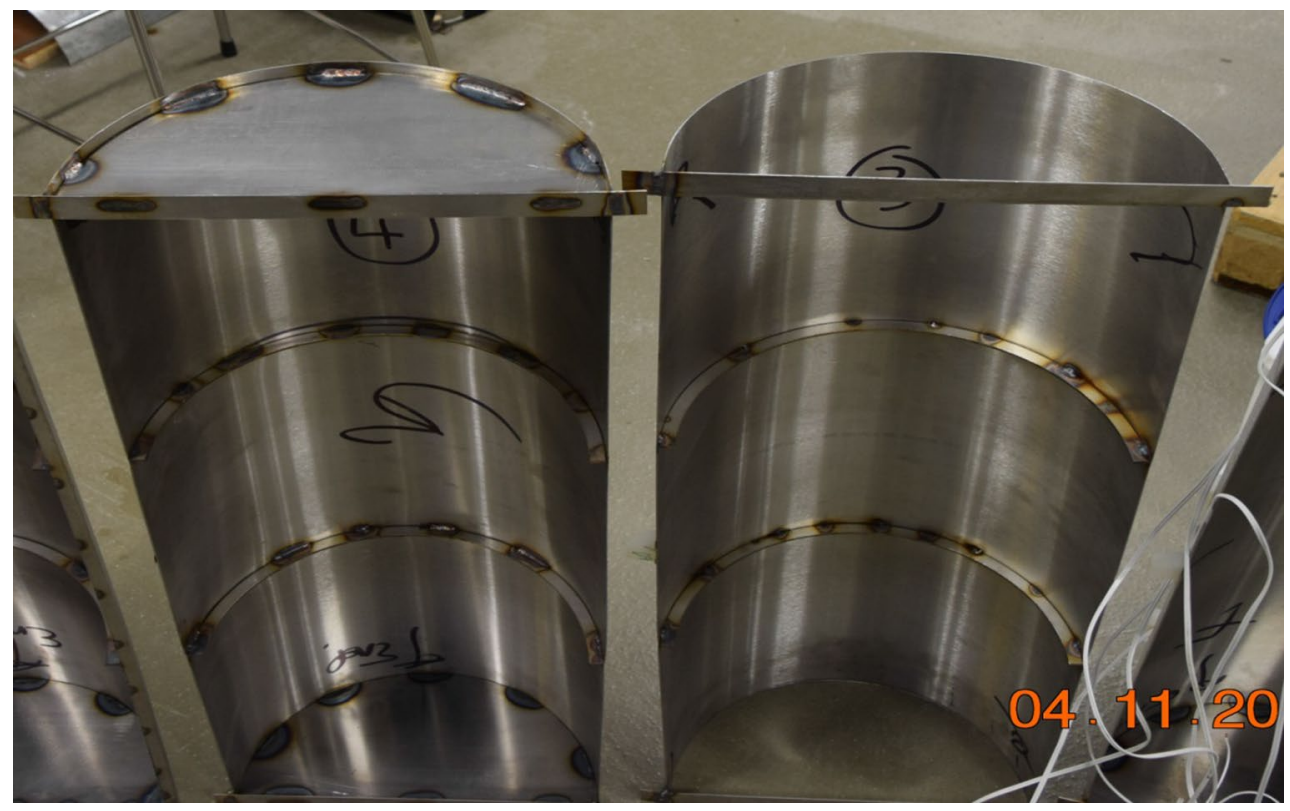

Fig. 9 Positioning of the stiffeners

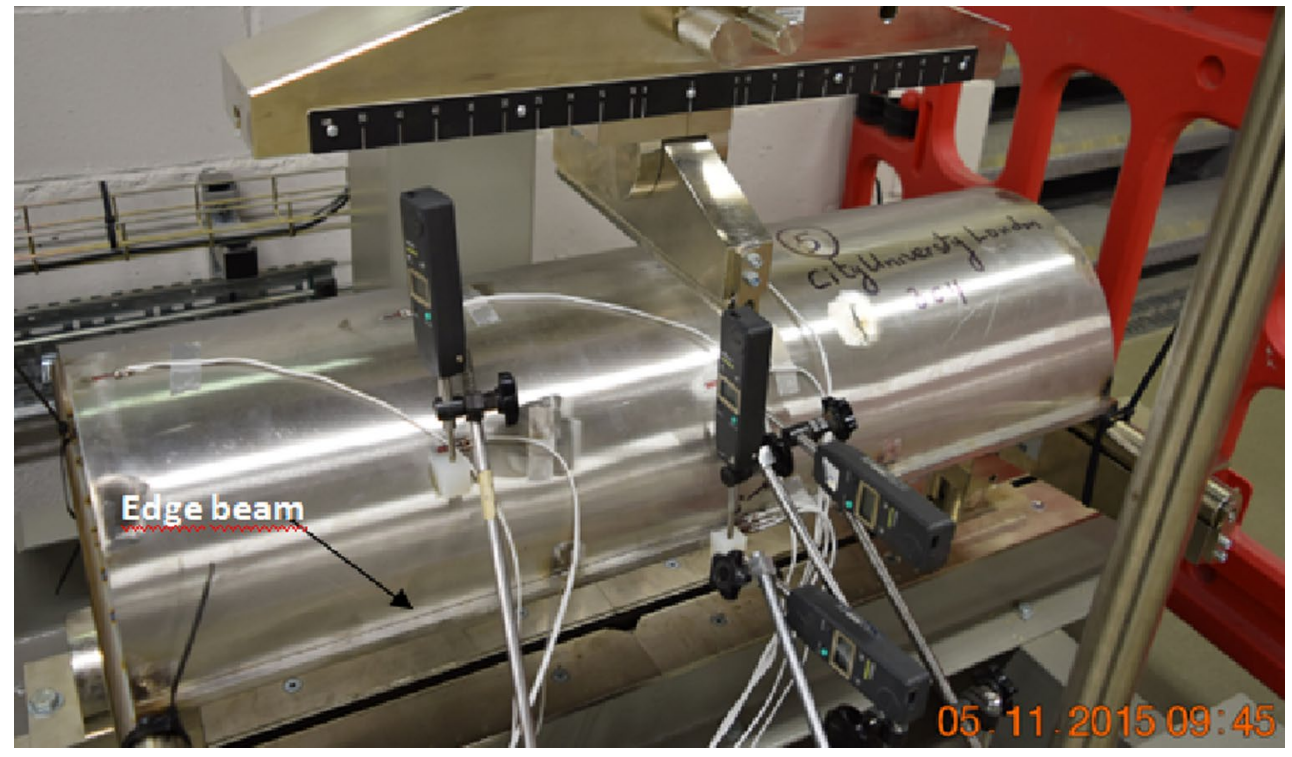

Fig. 10 Positioning of the edge beams

behavior for the end diaphragm, while a small level of deformations was observed in the tests.

\subsection{Comparison of Deflection Results Between CS4P and CSRD Using ACM-RSBE5 Element, ABAQUS Code and Experimental Results}

The vertical displacements at the top of the cylindrical shell models with no end diaphragms and the cylindrical shell with end Rigid Diaphragms with different loadings, and the percentage of reduction of the deflection by using ACMRSBE5 element, ABAQUS element and the experimental results are also presented in Table 1.

Table 1 shows that the deflection diminution percentage observed from the experimental results in the presence of the rigid diaphragm and is almost $68 \%$; that means that the rigid diaphragm minimized the vertical displacement at point 1 by $68 \%$, which is an excellent contribution. 


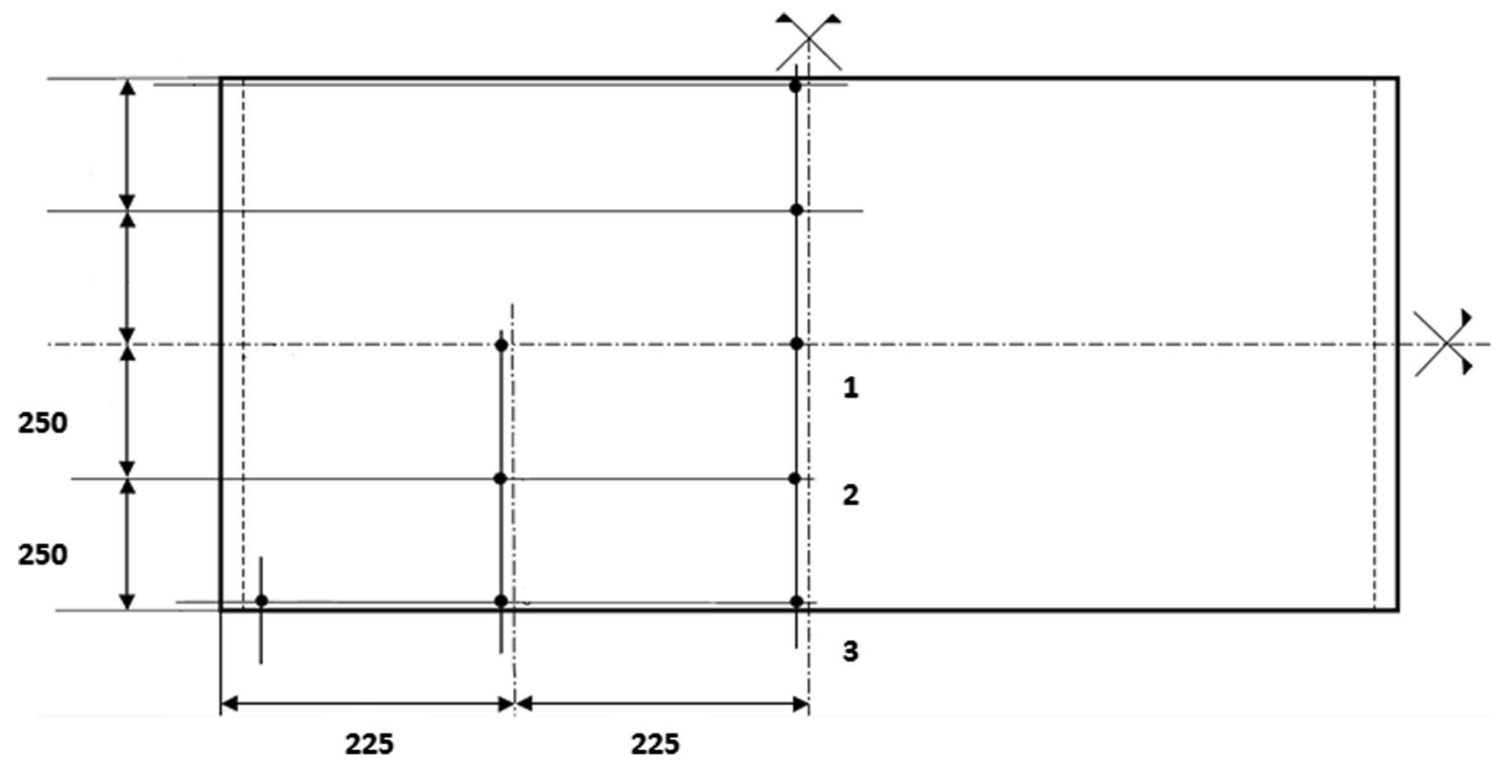

Fig. 11 Location of the points 1,2 and 3

Table 1 The deflection diminution percentage using ACM-RSBE5 element, ABAQUS element and the experimental results for the CS4P and CSRD at Point 1

\begin{tabular}{|c|c|c|c|c|c|c|c|c|c|}
\hline \multirow[t]{3}{*}{ Load $(\mathrm{N})$} & \multicolumn{3}{|c|}{ ACM-RSBE5 } & \multicolumn{3}{|c|}{ S4R ABAQUS } & \multicolumn{3}{|c|}{ Experimental solution } \\
\hline & \multicolumn{2}{|c|}{ Deflection (mm) } & \multirow[t]{2}{*}{ Percentage $(\%)$} & \multicolumn{2}{|c|}{ Deflection (mm) } & \multirow[t]{2}{*}{ Percentage $(\%)$} & \multicolumn{2}{|c|}{ Deflection (mm) } & \multirow[t]{2}{*}{ Percentage (\%) } \\
\hline & CS4P & CSRD & & CS4P & CSRD & & CS4P & CSRD & \\
\hline 775 & 5.061 & 1.064 & 78.97649 & 5.08 & 1.087 & 80.7165358 & 4.649 & 1.438 & 69.06862 \\
\hline 800 & 5.224 & 1.098 & 78.981623 & 5.241 & 1.122 & 80.70979 & 5.098 & 1.727 & 66.12397 \\
\hline 825 & 5.387 & 1.133 & 78.96789 & 5.403 & 1.157 & 80.69591 & 5.606 & 1.831 & 67.338566 \\
\hline 850 & 5.551 & 1.167 & 78.976761 & 5.564 & 1.192 & 80.69734 & 6.060 & 1.936 & 68.052805 \\
\hline 875 & 5.714 & 1.201 & 78.981449 & 5.726 & 1.227 & 80.684597 & 6.422 & 2.013 & 68.654625 \\
\hline 900 & 5.877 & 1.236 & 78.96886 & 5.888 & 1.262 & 0.216033 & 6.822 & 2.103 & 69.173263 \\
\hline
\end{tabular}

Fig. 12 The comparison of deflections for the cylindrical shell models with different boundary conditions (experimental and numerical results)

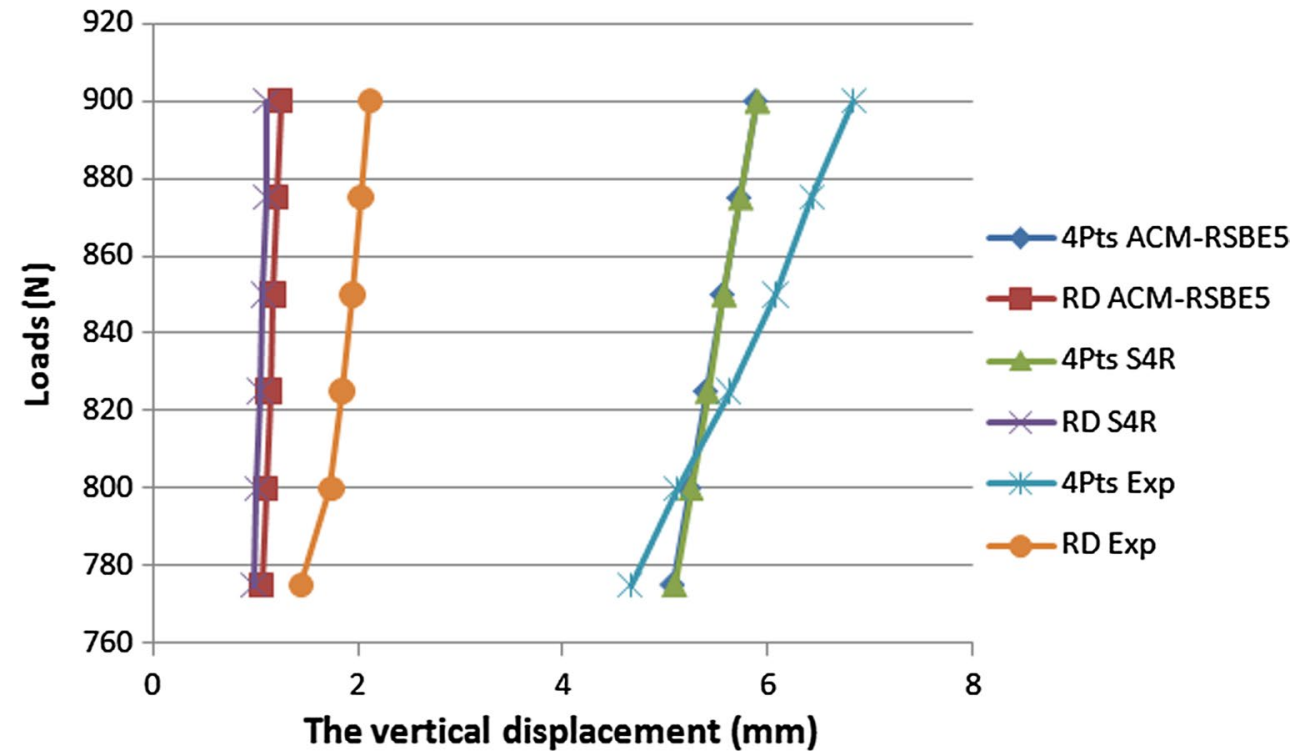


The deflection diminution percentage is almost $80 \%$ according to both the ACM-RSBE5 and ABAQUS results, indicating both models resulted in reasonable simulation of the behavior.

Figure 12 presents the analytical and experimental load-displacement curves for the cylindrical shell model reposed on 4 points and the cylindrical shell model reposed on two rigid diaphragms. For the deflection of the cylinder reposed on 4 points, the finite element results obtained with ACM-RSBE5 and S4R elements are very close. These results present a good agreement between the ACM_RSBE5 element, S4R element and those from the experimental tests. Also, for the cylinder model with end rigid diaphragm, the results obtained with both finite element models mentioned above are close to the experimental one. In Fig. 12, it can be observed that the diminutions of deflections using the rigid diaphragm are as follow: $68 \%$ for the experimental results, $79 \%$ for the ACM-RSBE5 finite element model and $80 \%$ for the ABAQUS model.

For the cylindrical shell model supported on four points, the load applied at the top of the cylinder spreads out on the skin and goes towards the supports "4 points"; but for the cylindrical shell supported by the rigid diaphragms, the load goes from the skin to the curved boundaries of the cylinder then to the rigid diaphragms reducing the vertical displacements.

\section{Effectiveness of Boundary Conditions Supports on the "Cylindrical Shell with Stiffeners"}

For the study of the effectiveness of rigid diaphragms on cylindrical shell structures with stiffeners, especially for deflections, experimental tests were performed on two models and the percentage of the vertical displacements between the stiffened cylindrical shell models reposed on four points "pinned" SCS4P and the stiffened cylindrical shell supported on two ends by Rigid Diaphragms SCSRD are compared.

\subsection{Comparison of Deflection Results Between SCS4P and SCSRD Using Experimental and ABAQUS Analysis Results}

The following values of the loads $(900 \mathrm{~N}, 950 \mathrm{~N}, 1000 \mathrm{~N}$, $1050 \mathrm{~N}$ and $1100 \mathrm{~N}$ ) are applied separately to the stiffened cylindrical shell reposed on four points and the stiffened cylindrical shell with end Rigid Diaphragms, the displacements results are computed and recorded in Table 2. Table 2 presents the vertical displacement at point 3 (Experimental and numerical results) for the stiffened cylindrical shell reposed on 4 points "pinned" SCS4P and the stiffened cylindrical shell supported on Rigid Diaphragms SCSRD with different loadings.

\subsection{Comparison of Deflection Diminution Between "SCS4P" and "SCSRD" Models with ABAQUS Analysis}

The percentage of deflection reduction for cylindrical shell models "SCS4P" and "SCSRD", from both the experimental and ABAQUS results are presented in Table 2.

From Table 2, the percentage of deflection diminution according to the experimental results ranges between 40 and $50 \%$. So, the use of a rigid diaphragm on the stiffened cylindrical shell minimized the vertical displacement at the top by around $45 \%$, representing an excellent contribution.

From Table 2, the percentage of deflection diminution according to the ABAQUS results is almost $45 \%$ indicating that the finite element model produced satisfactory results.

Figure 13 presents the difference of deflection between the stiffened cylindrical shell model reposed on 4 points and the stiffened cylindrical shell reposed on two end rigid diaphragms, for both the numerical and experimental results. For the deflection of the stiffened cylinder reposed on 4 points, the finite element model C3D8IH presents a good correlation to the experimental results.

Also, from Fig. 12, it can be seen that the diminution of deflection using the rigid diaphragm is between 40 and $50 \%$ for the experimental results and $44 \%$ for the ABAQUS model. The changing of boundary supports from the pinned
Table 2 The deflection diminution percentage using ABAQUS element and the experimental results for the SCS4P and SCSRD at point 3

\begin{tabular}{|c|c|c|c|c|c|c|}
\hline \multirow[t]{3}{*}{$\operatorname{Load}(\mathrm{N})$} & \multicolumn{3}{|c|}{ S4R ABAQUS } & \multicolumn{3}{|c|}{ Experimental solution } \\
\hline & \multicolumn{2}{|c|}{$\begin{array}{l}\text { Vertical displacement } \\
(\mathrm{mm})\end{array}$} & \multirow[t]{2}{*}{ Percentage (\%) } & \multicolumn{2}{|c|}{$\begin{array}{l}\text { Vertical displacement } \\
(\mathrm{mm})\end{array}$} & \multirow[t]{2}{*}{ Percentage (\%) } \\
\hline & SCS4P & SCSRD & & SCS4P & SCSRD & \\
\hline 900 & 2.595 & 1.447 & 44.238921 & 3.453 & 1.591 & 53.924124 \\
\hline 950 & 2.737 & 1.527 & 44.208988 & 3.529 & 1.755 & 50.269198 \\
\hline 1000 & 2.991 & 1.607 & 46.27215 & 3.806 & 1.607 & 57.777194 \\
\hline 1050 & 3.023 & 1.688 & 44.161429 & 3.829 & 2.138 & 44.162967 \\
\hline 1100 & 3.165 & 1.768 & 44.139021 & 3.966 & 2.355 & 40.620272 \\
\hline
\end{tabular}


Fig. 13 The comparison of deflections for the stiffened cylindrical shell models with different boundary conditions (experimental and numerical results)

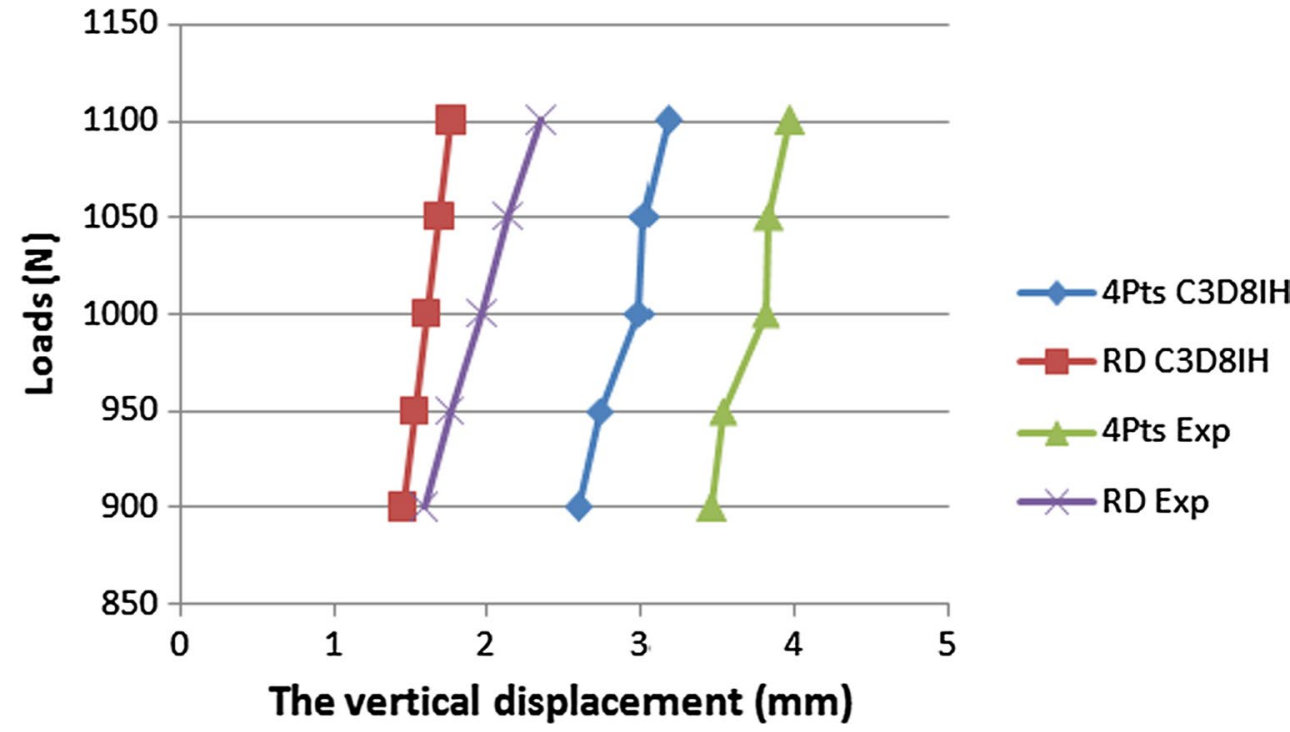

Table 3 The vertical displacement $\mathrm{W}_{1}$ at point 1 (experimental and ABAQUS results with meshes of $45 \times 25$ ) for the Cylindrical shell with two end diaphragms and two stiffeners "SCD"

\begin{tabular}{|c|c|c|}
\hline \multirow[t]{2}{*}{ Loads (N) } & \multicolumn{2}{|c|}{ Displacement $\mathrm{W}_{1}$ at point $1(\mathrm{~mm})$} \\
\hline & Experimental solution & $\begin{array}{l}\text { C3D8IH } \\
\text { ABAQUS }\end{array}$ \\
\hline 800 & 1.229 & 1.286 \\
\hline 850 & 1.398 & 1.366 \\
\hline 900 & 1.591 & 1.447 \\
\hline 950 & 1.795 & 1.527 \\
\hline 1000 & 1.966 & 1.607 \\
\hline 1050 & 2.138 & 1.688 \\
\hline
\end{tabular}

conditions to the rigid diaphragm reduces the vertical displacement of the stiffened cylindrical shell by about $40 \%$. In this case, by using ring stiffeners, the load is distributed from the skin to the stiffeners resulting in smaller deformations. The load is then transferred equally to the four supports. As a comparison, the stiffeners reduce the vertical displacement by about $70 \%$, and the addition of the rigid diaphragm reduces the vertical displacement by about $40 \%$. This is considered an excellent diminution to the deflection, and represents a great solution to improve the performance of the structure.

\section{Effectiveness of Edge Beams on the Stiffened Cylindrical Shells}

For the study of the effectiveness of the edge beams on the stiffened cylindrical shells; two semi cylindrical shells with rigid diaphragm are considered:
Table 4 The vertical displacement $\mathrm{W}_{1}$ at point 1 (experimental and ABAQUS results with meshes of $45 \times 25$ ) for the Cylindrical shell with two end diaphragms and two stiffeners resting on longitudinal beams "stringers" SCDS

\begin{tabular}{|c|c|c|}
\hline \multirow[t]{2}{*}{ Loads $(\mathrm{N})$} & \multicolumn{2}{|c|}{ Displacement $\mathrm{W}_{1}$ at point $1(\mathrm{~mm})$} \\
\hline & Experimental solution & $\begin{array}{l}\text { C3D8IH } \\
\text { ABAQUS }\end{array}$ \\
\hline 800 & 0.883 & 1.280 \\
\hline 850 & 0.958 & 1.360 \\
\hline 900 & 1.043 & 1.440 \\
\hline 950 & 1.143 & 1.520 \\
\hline 1000 & 1.229 & 1.600 \\
\hline 1050 & 1.482 & 1.681 \\
\hline 1100 & 1.686 & 1.761 \\
\hline 1150 & 1.913 & 1.841 \\
\hline 1200 & 2.162 & 1.921 \\
\hline 1250 & 2.469 & 2.001 \\
\hline 1300 & 2.722 & 2.081 \\
\hline
\end{tabular}

- Stiffened cylindrical shell supported on two ends "Rigid Diaphragms" "SCD".

- Stiffened cylindrical shell supported on two ends "Rigid Diaphragms" with two edge beams (Stringers) "SCDS".

In this comparison the same procedure as the previous one is followed. The vertical displacements are recorded at point 1 and the horizontal displacement at points 2 and 3. Tables 3 and 4 present the vertical displacements at the top of the model obtained by ABAQUS and experimental results for (SCD) and (SCDS). Table 5 presents the 
Table 5 Percentage of vertical displacements diminution with experimental results for the SCD and SCDS, at point 1

\begin{tabular}{llll}
\hline Load $(\mathrm{N})$ & $\begin{array}{l}\text { Displacement for } \\
\text { the SCD }(\mathrm{mm})\end{array}$ & $\begin{array}{l}\text { Displacement for } \\
\text { the SCDS }(\mathrm{mm})\end{array}$ & $\begin{array}{l}\text { Diminution } \\
\text { percentage } \\
(\%)\end{array}$ \\
\hline 800 & 1.229 & 0.883 & 28.15 \\
850 & 1.398 & 0.958 & 31.47 \\
900 & 1.591 & 1.043 & 34.44 \\
950 & 1.795 & 1.143 & 36.32 \\
1000 & 1.966 & 1.229 & 37.49 \\
1050 & 2.138 & 1.482 & 30.68 \\
1100 & 2.355 & 1.686 & 28.41 \\
1150 & 2.575 & 1.913 & 25.71 \\
1200 & 2.851 & 2.162 & 24.17 \\
1250 & 3.146 & 2.469 & 21.52 \\
1300 & 3.378 & 2.722 & 19.42 \\
\hline
\end{tabular}

percentage of diminution of the vertical displacements at point 1 using the experimental and ABAQUS results for the SCD and SCDS.

\subsection{Cylindrical Shell with Two end Diaphragms and Two Stiffeners $(t=1.2 \mathrm{~mm})$}

Table 3 presents the vertical displacement $\mathrm{W}_{1}$ at point 1 (Experimental and ABAQUS results with meshes of $45 \times 25)$

\subsection{Cylindrical Shell with Two end Diaphragms and Two Stiffeners Resting on Longitudinal Beams "Stringers" $(t=1.2 \mathrm{~mm})$}

Table 4 presents the vertical displacement $\mathrm{W}_{1}$ at point 1 (Experimental and ABAQUS results with meshes of $45 \times 25)$.

\subsection{Percentage of Vertical Deflection Diminution Between "SCD" and "SCDS" Models with Experimental Results and Numerical Analysis}

Table 5 presents the percentage of vertical displacements diminution from the experimental results for the SCD and SCDS, at point 1.

For the experimental results shown in Table 5, the effect of longitudinal beams "Stringers" added to the cylindrical shell with two end diaphragms and two stiffeners is very high; the vertical displacement reduction is about $20-38 \%$.
Table 6 Percentage of horizontal displacements diminution with experimental results for the SCD and SCDS, at point 2

\begin{tabular}{llll}
\hline Load $(\mathrm{N})$ & $\begin{array}{l}\text { Displacement for } \\
\text { the SCD }(\mathrm{mm})\end{array}$ & $\begin{array}{l}\text { Displacement for } \\
\text { the SCDS }(\mathrm{mm})\end{array}$ & $\begin{array}{l}\text { Diminution } \\
\text { percentage } \\
(\%)\end{array}$ \\
\hline 1000 & 0.24 & 0.09 & 91.67 \\
1100 & 0.28 & 0.109 & 85.71 \\
1200 & 0.33 & 0.119 & 75.76 \\
1300 & 0.39 & 0.129 & 66.67 \\
1400 & 0.47 & 0.139 & 59.57 \\
\hline
\end{tabular}

Table 7 Percentage of horizontal displacements diminution with ABAQUS results for the SCD and SCDS, at point 2

\begin{tabular}{llll}
\hline Load $(\mathrm{N})$ & $\begin{array}{l}\text { Displacement for } \\
\text { the SCD }(\mathrm{mm})\end{array}$ & $\begin{array}{l}\text { Displacement for } \\
\text { the SCDS }(\mathrm{mm})\end{array}$ & $\begin{array}{l}\text { Diminution } \\
\text { percentage } \\
(\%)\end{array}$ \\
\hline 1000 & 0.147 & 0.09 & 38.77 \\
1100 & 0.162 & 0.109 & 32.72 \\
1200 & 0.177 & 0.119 & 32.77 \\
1300 & 0.192 & 0.129 & 32.81 \\
1400 & 0.207 & 0.139 & 32.85 \\
\hline
\end{tabular}

Table 8 Percentage of horizontal displacements diminution with experimental results for the SCD and SCDS, at point 3

\begin{tabular}{llll}
\hline Load $(\mathrm{N})$ & $\begin{array}{l}\text { Displacement for } \\
\text { the SCD }(\mathrm{mm})\end{array}$ & $\begin{array}{l}\text { Displacement for } \\
\text { the SCDS }(\mathrm{mm})\end{array}$ & $\begin{array}{l}\text { Diminution } \\
\text { percentage } \\
(\%)\end{array}$ \\
\hline 1000 & 0.47 & 0.21 & 55.32 \\
1100 & 0.57 & 0.29 & 49.12 \\
1200 & 0.70 & 0.39 & 44.29 \\
1300 & 0.85 & 0.52 & 38.82 \\
1400 & 1.03 & 0.67 & 34.95 \\
1500 & 1.25 & 0.87 & 30.40 \\
\hline
\end{tabular}

\subsection{Percentage of Horizontal Displacements Diminution at Point 2 Using the Experimental and Numerical Results}

Tables 6 and 7 present the percentage of horizontal displacements diminution at point 2 using the experimental and ABAQUS results for the SCD and SCDS.

From the results obtained in Table 6, the percentage of horizontal displacements diminution at point 2 varied between 59 and $91 \%$; so the longitudinal beams presented a good contribution to the behavior in this case. Meanwhile; the percentage obtained by ABAQUS element is almost stable at $32 \%$ for all applied loads. 
Table 9 Percentage of horizontal displacements diminution with ABAQUS results for the SCD and SCDS, at point 3

\begin{tabular}{llll}
\hline Load $(\mathrm{N})$ & $\begin{array}{l}\text { Displacement for } \\
\text { the SCD }(\mathrm{mm})\end{array}$ & $\begin{array}{l}\text { Displacement for } \\
\text { the SCDS }(\mathrm{mm})\end{array}$ & $\begin{array}{l}\text { Diminution } \\
\text { percentage } \\
(\%)\end{array}$ \\
\hline 1000 & 0.651 & 0.394 & 39.48 \\
1100 & 0.717 & 0.434 & 39.47 \\
1200 & 0.783 & 0.475 & 39.34 \\
1300 & 0.848 & 0.515 & 39.27 \\
1400 & 0.914 & 0.555 & 39.28 \\
1500 & 0.980 & 0.596 & 39.18 \\
\hline
\end{tabular}

\subsection{Percentage of Horizontal Displacements Diminution at Point 3 Using the Experimental and Numerical Results}

Tables 8 and 9 present the percentage of horizontal displacements diminution at point 3 using the experimental and numerical results, for the SCD model and SCDS model.

The same previous comments for point 2 can be given for the diminution of horizontal displacement for point 3 (Tables 8,9 ), and the average is around $40 \%$ for both numerical and experimental results in the presence of longitudinal beams "Stringers".

These results confirm that a very good diminution of the horizontal displacements, especially at points 2 and 3 , is observed. In this case, when the load is applied at the top of the cylinder, the stringers obstruct the tendency of the straight borders to deform reducing the horizontal displacements.

\section{Conclusions}

From the results obtained by the experimental investigation and numerical analysis presented above, the following points can be drawn:

For all tests done and presented above, acceptable results are obtained for the numerical analysis in comparison the experimental work.

1. A significant effect on deflections can be obtained by the Rigid Diaphragms; the percentage of displacement reduction is close to $68 \%$ from the experimental observations, and $80 \%$ from the ACM-RSBE5 element and the ABAQUS code. That means the vertical displacement at the top of cylinder "the point of applied the load" is minimized by $68 \%$ when using the Rigid Diaphragms. So a high percentage of deflection reduction can be achieved with Rigid Diaphragms. This is due to the fact that when using rigid diaphragms, the effect goes from the skin to the curved boundaries of the cyl- inder then to the rigid diaphragms. So, the cylinder with rigid diaphragms can support much higher loads with smaller deformations.

2. The same previous comment can be concluded for the stiffened cylindrical shell supported on 4 points and the stiffened cylindrical shell model with two end Rigid Diaphragms; good results can be obtained when using Rigid Diaphragms, the percentage of deflection reduction is close to $50 \%$ from the experimental results and 45\% from the ABAQUS analysis. That means that the rigid diaphragms minimized the deflection to the half. In this case, by using ring stiffeners, the load pressure is distributed from the skin to the stiffeners resulting in smaller deformations. The load is then transferred equally to the four supports.

3. The stiffeners have an important effect on the deflection of cylindrical shell structures; but the efficiency of boundary conditions is more significant than the stiffeners, especially for the locations of stiffeners adopted in the experimental tests presented in this work.

4. Both rigid diaphragms and stiffeners play an important role in minimizing the deflections of shell structures; that means their presence can result in good design and reduce the economic cost of the structure.

5. The effectiveness of edge beams is very important as concluded from the experiment. The reduction is about 20-38\% for the vertical displacement of point 1, varied between 59 and $91 \%$ for the horizontal displacements of point 2 , and is $40 \%$ for the horizontal displacement at point 3 . When using stringers, they obstruct the tendency of the straight borders to deform reducing the horizontal displacements.

6. The numerical modeling approach used in this work proves its efficiency compared to the experimental results for the case of cylindrical shells with and without stiffeners.

Acknowledgements The authors would like to thank all people involved in this work at the Structural Engineering laboratory of City, University of London. Special thanks are due to Dr. Brett McKinley, the laboratory manager for his invaluable advices regarding the test rig setup, Mr. JN Hooker the laboratory technician for the preparation of models, as well as Mr. S Gendy, Mr. R. Mohammad, and Mr. D Das for their help to construct the models.

Open Access This article is distributed under the terms of the Creative Commons Attribution 4.0 International License (http://creativeco mmons.org/licenses/by/4.0/), which permits unrestricted use, distribution, and reproduction in any medium, provided you give appropriate credit to the original author(s) and the source, provide a link to the Creative Commons license, and indicate if changes were made. 


\section{References}

ABAQUS. (2014). Version 6.14, Dassault Systemes Simulia Corp.

Adini, A., \& Clough, R. W. (1961). Analysis of plate bending by the finite element method. USA: Report to the National Science Foundation.

Chebili, R. (1991). The boundary support of shells. Ph.D. Thesis. UK: University of Bath.

Flügge, W. (1934). Stresses in shells. Berlin: Springer.

Forsberg, K. (1964). Influence of boundary conditions on the modal characteristics of thin cylindrical shells. AIAA Journal, 2(12), 2150-2157.

Hamadi, D., Ayoub, A., \& Abdelhafid, O. (2015). A new flat shell finite element for the linear analysis of thin shell structures. European Journal of Computational Mechanics, 24(6), 232-255.

Marchuk, A. V., \& Gnidash, S. V. (2016). Analysis of the effect of local loads on thick-walled cylindrical shells with different boundary conditions. International Applied Mechanics, 52(4), 368-377.
Melosh, R. J. (1963). Basis of derivation of matrices for the direct stiffness method. AIAAJ, 1(7), 1631-1637.

Skukis, E., Kalniņš, K., \& Ozolinšs, O. (2013). Assessment of the effect of boundary conditions on cylindrical shell modal responses. In Proceedings of civil engineering 13: 4th international scientific conference (Vol. 4(1), pp. 41-48). Jelgava, Latvia: Latvia University of Agriculture.

Sobel, L. (1964). Effects of boundary conditions on the stability of cylinders subject to lateral and axial pressures. AIAAJ, 2(8), $1437-1440$

Wilkins, D. J., Jr., Bert, C. W., \& Egle, D. M. (1970). Free vibrations of orthotropic sandwich conical shells with various boundary conditions. Journal of Sound and Vibration, 13(2), 211-228. 